\title{
Psychological and pedagogical prevention of emotional burnout in teachers
}

\author{
I.R. Pozdnyakova ${ }^{1 *}, T . N$. Taranova ${ }^{2}$, and I.V. Misherina ${ }^{3}$ \\ ${ }^{1}$ Gzhel State University, Elektroizolyator, Russia \\ ${ }^{2}$ North Caucasus Federal University, Stavropol, Russia \\ ${ }^{3}$ North Caucasus Federal University, Stavropol, Russia
}

\begin{abstract}
The article is devoted to studying the problem of emotional burnout syndrome in teachers. The development of burnout syndrome in teachers is influenced by organizational and individual factors. Organizational factors include the conditions of the material environment, the content of work, and socio-psychological conditions of activity. The group of individual factors that affect the development of emotional burnout syndrome in teachers includes socio-demographic (age, experience, gender) and personal characteristics. According to the authors, emotional burnout is a link between a person and the environment. And the task of participants in the educational process is timely work to prevent the impact of potential "provocateurs" of burnout syndrome.
\end{abstract}

\section{A problem statement}

In the context of changes taking place in Russian society, the problem of the effectiveness of professional activity, including in the field of education, is particularly relevant. In order to ensure and maintain a high level of activity of teaching staff in educational organizations, it is necessary to pay attention to such a psychological aspect as emotional burnout of teachers. According to statistics, from $12 \%$ to $48 \%$ of teachers have a formed burnout syndrome. Burnout is essentially a response to chronic emotional stress, a consequence of "mental overwork".

The relevance of the research is that a modern teacher is called upon to solve problems that require serious pedagogical efforts. Mastering new content, forms and methods of teaching, search for effective ways of education, the need to take into account the very rapid changes taking place in society and the information field of activity - all this is only possible for a psychologically healthy, professionally competent, creatively working teacher. The psychological health of the teacher largely depends on the psychological health of his pupils. The effect of numerous emotsiogenic factors (both objective and subjective) causes teachers to have a growing sense of dissatisfaction, deterioration of health and accumulation of fatigue. These physiological indicators characterize the intensity of work, which leads to the formation of symptoms of burnout syndrome. The result of these processes is a decrease in the quality of professional activity of the teacher: he can no

${ }^{*}$ Corresponding author: prof-ped.gpa@mail.ru 
longer cope with his duties, loses his creative attitude towards the subject and product of his work, and deforms his professional relationships and roles.

Thus, the burnout syndrome is one of the most common barriers to professionalism, creativity and self-realization of an employee of an educational organization.

\subsection{The objective of the work}

The problems of professional formation and development of the subject, the formation of an individual style of activity are covered in the works of K.A. Abulkhanova-Slavskaya [1], B.G. Ananyev [2], E.A. Klimov [3], A.N. Leontiev, V.D. Shadrikov [4] and other classics of Russian psychology. More specific issues of negative variants of personality development in the profession - professional deformations, destructions, deviant behavior are the Central theme in the works of S.P. Beznosov [5], P.M. Granovskaya, T.A. Zhalagina [6], E.F. Zeer [7], E.Yu. Pryazhnikova [8] and others. General and specific issues of psychological prevention of professional burnout are widely covered in modern scientific sources, candidate and doctoral dissertations (D.A. Andreeva, N.E. Vodopyanova [9], G.S. Nikiforov, L.S. Pavlova, etc.).

From our point of view, the problem of emotional burnout syndrome is most objectively studied in the works of the American psychiatrist H.J. Fredenberger, social psychologist K. Maslach [10], in which they define emotional burnout as physical and emotional exhaustion and loss of full perception of the surrounding reality, including in professional activities. Among the domestic publications of recent years, it should be noted, first of all, the works of V.V. Boyko [11], which describe in detail the actual burnout syndrome, its stages of formation and characteristic symptoms.

The given brief review, which characterizes the degree of scientific development of the problem under consideration, allows us to state that today a fairly detailed theoretical, conceptual and methodological base for its study has been formed, verified in a number of experimental studies. However, the development of organizational and methodological conditions related to the provision of psychological and pedagogical prevention of burnout syndrome in employees of educational organizations becomes particularly relevant when considering this problem.

The term "burnout syndrome "was born relatively recently: almost fifty years ago (in 1974), the American psychiatrist H.J. Freudenberg, together with G. Norton, were able to interpret the concept of burnout syndrome and defined it as" a gradual process of loss of emotional, cognitive and physical energy by a person, accompanied by symptoms of emotional and mental exhaustion, frequent physical fatigue, personal detachment and lack of satisfaction with the work performed". This definition is still relevant to this day.

The most complete and well-founded classification of burnout symptoms is considered to be the classification proposed by V. Schaufelli et Al. Enzmann. The authors identified 132 symptoms of burnout, which they combined into 5 main groups:

1) affective;

2) cognitive;

3) physical;

4) behavioral;

5) motivational.

From the authors' point of view, burnout symptoms appear on three levels: individualpsychological, interpersonal, and organizational [12].

K. Chernis identifies three stages of professional burnout:

1. The first stage is characterized by an imbalance between resources and requirements of the environment that creates stress. 
2. In the second stage, the employee experiences short-term emotional stress, fatigue, and exhaustion.

3. The third stage is manifested in changes in the motivational sphere of the professional and his behavior, where the leading symptom is inhumane (soulless) treatment of others [13].

The leading determinant of burnout is the adequacy of the method chosen by the subject to overcome stress.

Despite the undoubted contribution to the study of professional burnout, the procedural models proposed by Western psychologists are mostly descriptive. They are distinguished by their heterogeneity and mosaic nature, which reduce their practical value.

In foreign studies of the phenomenon of emotional burnout, there are two main points of view in its understanding. Burnout is understood either as a complex of relatively independent symptoms that are combined into larger blocks, or as a process that accompanies professional development of a person and has a stadium character.

A significant number of empirical studies within this approach are aimed at identifying the role of personal characteristics in the formation of signs of emotional burnout.

H.J. Freudenberger describes "burnout" of professionals as sympathetic, humane, soft, enthusiastic, idealistic, people-oriented, and, at the same time, unstable, introverted, obsessive (fanatical), "fiery" and easily identifying [14].

E. Maher identifies authoritarianism and a low level of empathy as factors that initiate burnout.

\section{Results of the research}

After identifying the problem, experimental work was carried out to identify the level of emotional burnout of the individual in employees of educational organizations in order to identify the degree of formed burnout syndrome.

The test subjects were 35 teachers from educational organizations in the city of Stavropol: 2 teachers $(6 \%)$ under the age of 30,11 teachers $(31 \%)$ between the ages of 30 and $40 ; 18$ teachers $(51 \%)$ between the ages of 41 and 55 ; and 4 teachers $(11 \%)$ older than 55.

Depending on the work experience of teachers, the subjects can be divided into the following groups:

work experience $0-5$ years - $14 \%$ ( 5 teachers);

work experience of 5-10 years - 66\% (23 teachers);

work experience of more than 10 years $-20 \%$ ( 7 teachers).

To diagnose emotional burnout of employees of educational organizations there is a method of K. Maslach and S. Jackson. This technique allows you to identify such components of emotional burnout as:

1. Emotional exhaustion.

2. Depersonalization.

3. Reduction of professionalism.

Analyzing such a component of the burnout syndrome as emotional exhaustion, we found a high level in $40 \%$ of respondents, which indicates a decrease in emotional tone, loss of interest in the world and events, emotional saturation, frequent aggressive reactions and outbursts of anger, and the appearance of symptoms of depression in this category of respondents. $31 \%$ showed an average level of emotional exhaustion, $29 \%$ of respondents have a low level of emotional exhaustion (Fig. 1): 


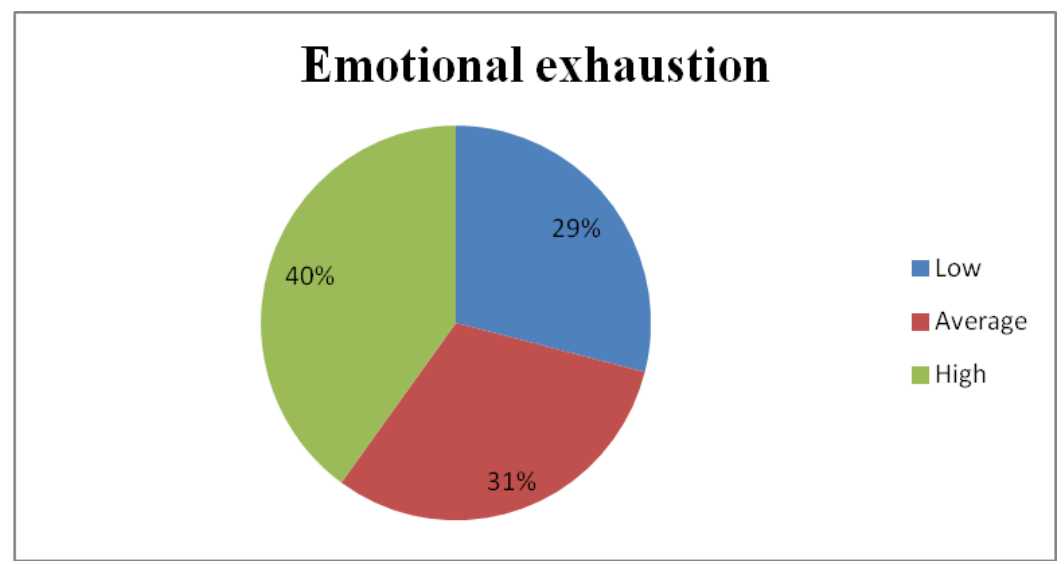

Fig. 1. Level of emotional exhaustion.

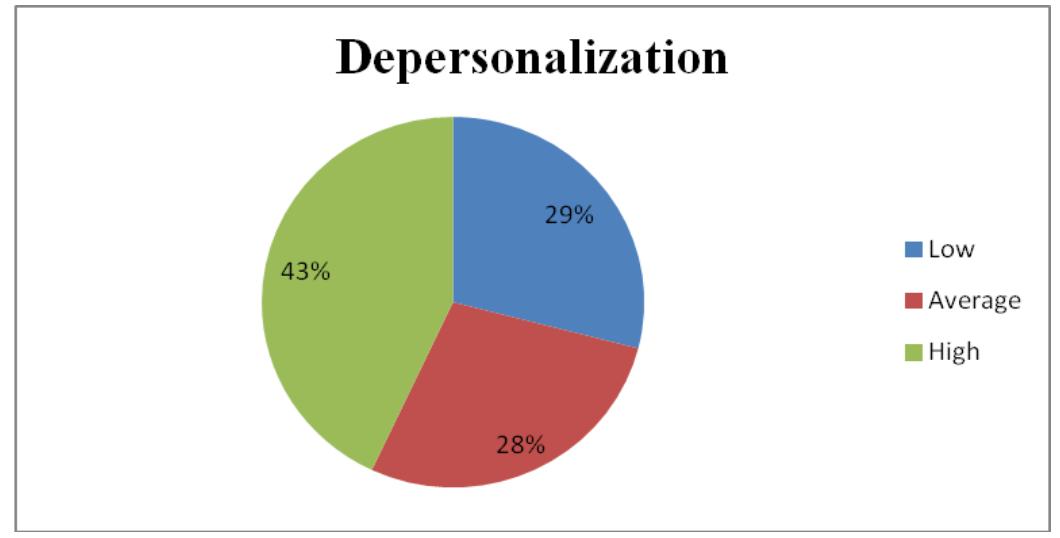

Fig. 2. Depersonalization.

The polls showed a high level of depersonalization in $43 \%$ of the interviewed teachers of educational organizations, an average level - in $28 \%$ and a low level - in $29 \%$. A high level of depersonalization appears in emotional detachment and indifference, formal performance of professional duties (Fig. 2).

High and medium levels of reduction of professionalism are observed equally in $37 \%$ of respondents, low level - in $26 \%$. A high level of professional reduction in $37 \%$ of respondents suggests that this category of teachers has a tendency to negatively evaluate them, reduce the significance of their own achievements, reduce self-esteem and professional motivation. For this category of respondents, the reduction may be manifested in attempts to ease or reduce responsibilities that require emotional costs. Frequent tea parties, work breaks, etc. It should also be noted that the result of diagnostics of the level of reduction of professionalism in $7 \%$ of respondents from among the surveyed teachers with an average level of reduction is on the border with a high level of reduction (Fig. 3). 


\section{Reduction of professionalism}

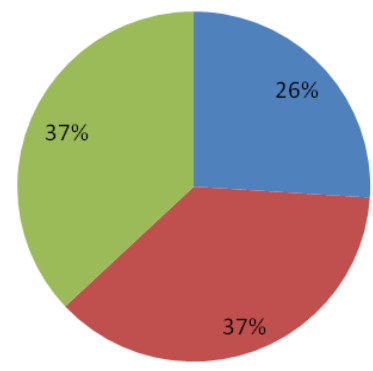

Average

High

Fig. 3. Reduction of professionalism.

Calculation of the integral level of emotional burnout showed the presence of formed burnout syndrome in $41.2 \%$ of the surveyed employees of educational organizations. It is worth noting that the syndrome of emotional burnout according to the results of the diagnosis was formed in teachers who are in the position from 7 to 10 years and aged 37-55 years. It is interesting to note that out of 35 respondents, the lowest indicators for all 37 sub-schools were shown by 2 male teachers under the age of 30 who have been in the position for 1-2 years and 4 female teachers over the age of 55 who have been in the position for more than 23 years.

Indicators for all three subscales identified during the diagnostics of the level of emotional burnout of employees of educational organizations in Stavropol using the method of K. Maslach, in addition to the presence of formed burnout syndrome in $41.2 \%$ of the surveyed teachers, clearly indicate a high risk of developing burnout syndrome in $37 \%$ of the respondents. These indicators prove again the need for purposeful work to prevent emotional burnout of a teacher in a modern educational organization.

In $100 \%$ of cases, teachers showed interest in the test, which was expressed in a request to send an interpretation of the questionnaire in a response letter. Also, during a remote conversation with 4 teachers of educational organizations from among the above-mentioned respondents, we found out that the prevention of burnout syndrome is a very interesting and relevant topic for them personally.

In April - May 2020, 35 teachers of educational organizations in Stavropol, who took part in the diagnosis of the level of emotional burnout using the method of K. Maslach, also took part in the survey. The questionnaire consisted of 3 questions with no possible answers:

1. What is burnout?

2. What are the main causes of emotional burnout of a teacher in a modern educational organization?

3. What should be done so that the teacher "does not burn out" at work?

At the beginning of the questionnaire, we asked respondents not to use scientific sources when answering questions, but to formulate their thoughts in the "here and now" format, based on their personal understanding. 


\section{Results of the survey}

consequences of the

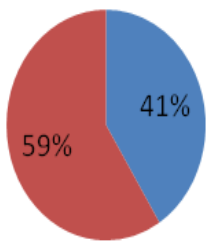

development of the

syndromeitself

emotional exhaustion

Fig. 4. Results of the survey.

The absolute majority of subjects, answering the question: What is emotional burnout (EB)? EB was considered as a professional phenomenon. $41 \%$ of respondents named the causes, symptoms, or consequences of the development of the syndrome itself as the definition of EB. For example, "EB is a lack of desire to go to work, do something..."; "...lack of moral and psychological satisfaction from work"; "...lack of positive emotions, constant stress»; "...the inability to find the right solution to the problem...", " ...when you stop understanding your subordinates, you can't step over your "I"..." and so on. 59\% of respondents used the concept of "emotional exhaustion" as the definition of EB. Thus, teachers of modern educational organizations can only give an incomplete definition of the concept of emotional burnout, often replacing the phenomenon of EB with (EBS) of its development.

The reasons for the development of emotional burnout syndrome in a teacher of an educational organization, based on the responses of respondents, are the following:

1. "Heavy load" - 99\% of respondents described this as one of the main and first reasons for EBS.

2. "Dissatisfaction with work" as the actual wording is found in $85 \%$ of the responses along with the "high responsibility" ("you are responsible for all and for everything, even for something not to blame herself", "giperresponsibility"; etc.).

3. $75 \%$ of respondents indicated as the cause of the EBS excessive paperwork ("too much paperwork", "some solid records, there's no time to really work", "workload paper", etc.).

4. $29 \%$ of respondents "desire for idealism" ("desire to do everything perfectly", "trying too hard to do a good job", etc.).

$5.14 \%$ of subjects somehow indicated a lack of recognition or praise from employees.

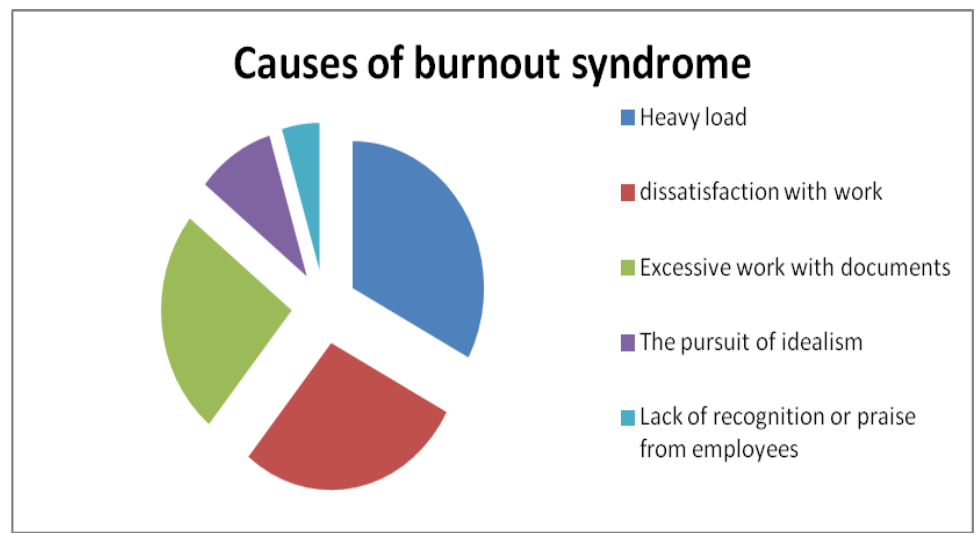

Fig. 5. Causes of burnout syndrome. 
Based on the answers to this questionnaire question, we can conclude that teachers of modern educational organizations quite accurately determine the causes of the development of burnout syndrome. However, it is worth noting that all the reasons for the development of EBS indicated by teachers in the questionnaires are directly related to their personal experience. They were more likely to describe their personal workplace stress factors. The answers to this question were the most complete and detailed in all the questionnaires. Some managers indicated 10 to 12 reasons for the development of EBS.

When answering the last question of the questionnaire "What should I do to prevent a teacher from "burning out" at work?" 98\% of respondents answered: "learn to relax (rest)." When answering this question, teachers of educational organizations often pointed out the need to lead a healthy lifestyle and doing sports. $65 \%$ of respondents mentioned various ways of self-development as prevention of EBS: "trainings", "courses", "seminars", "hobbies", "visiting museums, theaters and movies". We should also note such answers as: "you need to change your attitude to work", "learn to manage time", "leave on time", "apply positive thinking and love yourself", "a person needs to feel needed". The answers to the last question prove that teachers of modern educational organizations have only a general idea of the prevention of burnout syndrome, indicating individual private methods as a system of prevention as a whole. Analyzing the answers to the questionnaire, we also came to the conclusion that the phenomenon of emotional burnout is interesting for teachers of educational organizations, they themselves see risk factors for the development of EBS in their professional activities, and the topic of EBS prevention is relevant for teachers of modern educational organizations. The results of the survey also indicate that teachers are familiar with certain prevention measures. However, the need is to create a system of interrelated measures aimed at preventing emotional burnout, in other words, creating a model for preventing emotional burnout of a teacher in a modern educational organization.

The results obtained in the course of diagnostics of the EB level of employees of educational organizations using the method of K. Maslach and S. Jackson [15] and conducting a survey confirmed the need for targeted work, namely, the creation of a program for the prevention of emotional burnout of a teacher in a modern educational organization.

Program of psychological and pedagogical prevention of emotional burnout in employees of educational organizations.

The purpose of the program: psychological and pedagogical prevention of emotional burnout of employees of educational organizations.

Research problem:

1. to develop a program for the prevention of emotional burnout of employees of educational organizations;

2. to analyze the effectiveness of the presented program for the prevention of burnout syndrome of employees of educational organizations;

3. to develop a technological map for the implementation of the program for the prevention of burnout among employees of educational organizations.

Creating a program for the prevention of burnout syndrome for employees of educational organizations, our main goal was to reduce stress, assuming work at three levels: the individual level, which involves the development of adaptive forms of employee behavior; the interpersonal level, which involves optimizing relationships with colleagues, students, and family members; the organizational level, which includes issues of optimizing the situation at work, improving working conditions, and so on.

The main attention was paid to the activities carried out at the individual (personal) level. Within the framework of such events, both correctional and training tasks were solved, as well as directly therapeutic tasks. Intervention at the individual level included: regime measures; psychotherapeutic correction (Table 1). 
Table 1. Program of psychological and pedagogical prevention of emotional burnout in employees of educational organizations "Kaleidoscope of emotions».

\begin{tabular}{|c|c|c|c|c|}
\hline № & $\begin{array}{l}\text { Form of } \\
\text { work }\end{array}$ & Title of lesson & Purpose and objectives & Time \\
\hline 1 & Lesson 1 & $\begin{array}{l}\text { Information-diagnostic } \\
\text { lesson }\end{array}$ & $\begin{array}{l}\text { Acquaintance, establishing } \\
\text { contact, adapting group members. } \\
\text { Informing teachers about } \\
\text { professional burnout syndrome, } \\
\text { its phases and symptoms; } \\
\text { diagnostics to detect "burnout", } \\
\text { forming queries. }\end{array}$ & 6 hours \\
\hline 2 & Lesson 2 & $\begin{array}{l}\text { "Rainbow of emotions } \\
\text { in our life" }\end{array}$ & 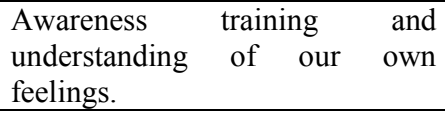 & 6 hours \\
\hline 3 & Lesson 3 & $\begin{array}{l}\text { "Stress in educational } \\
\text { activities" }\end{array}$ & $\begin{array}{l}\text { Establishing empathy, } \\
\text { cooperation. Development of } \\
\text { trusting relationships. Developing } \\
\text { the ability to name and be aware } \\
\text { of your emotions. }\end{array}$ & 6 hours \\
\hline 4 & Lesson 4 & $\begin{array}{l}\text { Communication } \\
\text { abilities }\end{array}$ & $\begin{array}{l}\text { Verbalization training your } \\
\text { emotional states, positive } \\
\text { interaction in a group, } \\
\text { development of verbal and non- } \\
\text { verbal communication skills, } \\
\text { development of adequate } \\
\text { expression skills your feelings. }\end{array}$ & 6 hours \\
\hline 5 & Lesson 5 & $\begin{array}{l}\text { Conflicts and their } \\
\text { consequences }\end{array}$ & $\begin{array}{l}\text { Training in ways of adequate } \\
\text { perception of their emotions, } \\
\text { modification of ways of } \\
\text { emotional experiences and } \\
\text { emotional response. }\end{array}$ & 7 hours \\
\hline 6 & Lesson 6 & $\begin{array}{l}\text { Creativity in our } \\
\text { school life }\end{array}$ & $\begin{array}{l}\text { Training techniques for self- } \\
\text { regulation of the mental state } \\
\text { through creativity through art } \\
\text { therapy. }\end{array}$ & 5 hours \\
\hline 7 & Lesson 7 & $\begin{array}{l}\text { Method of reading } \\
\text { aloud } \\
\text { (by Popova M.V.) }\end{array}$ & $\begin{array}{l}\text { Formation of positive self- } \\
\text { perception. }\end{array}$ & 4 hours \\
\hline 8 & Lesson 8 & $\begin{array}{l}\text { Reflexive training } \\
\text { (by Popova M.V.) }\end{array}$ & $\begin{array}{l}\text { Teaching methods of self- } \\
\text { regulation of the mental state, the } \\
\text { formation of a positive self- } \\
\text { perception. }\end{array}$ & 4 hours \\
\hline 9 & Lesson 9 & $\begin{array}{l}\text { Autogenic training } \\
\text { (by Popova M.V.) }\end{array}$ & $\begin{array}{l}\text { Training in self-regulation of } \\
\text { mental state. }\end{array}$ & 6 hours \\
\hline 10 & Lesson 10 & Final lesson & $\begin{array}{l}\text { Re-diagnosis, reflection of the } \\
\text { experience } \\
\text { recommendations. }\end{array}$ & 4 hours \\
\hline
\end{tabular}

Directions of preventive work:

- Mini-lectures that increase teachers ' psychological knowledge;

- Practical training on the development of psychological culture of the teacher (games, trainings, exercises).

Performance is tracked based on psychological diagnostics.

Psychotherapy techniques:

- music therapy; 
- relaxation;

- art therapy;

- aromatherapy;

- autogenic training;

- elements of body-oriented therapy;

- reflexive training.

The volume of our program was at a frequency of once a week:

- 9 informational and practical classes;

-1 reflexive training;

- 2 diagnostic events (primary and final).

\section{Conclusions}

Modern professional activity is characterized by psychoemotional overstrain, the resulting manifestations of which are depression, anxiety, psychosomatic disorders, various diseases and burnout syndrome. Stress is a powerful enough catalyst for the development of various diseases in humans, including it is one of the causes of burnout syndrome.

In the scientific literature, there is no consensus on what constitutes a burnout syndrome, how such phenomena as "stress" and "burnout" are interrelated and what are the differences. In this regard, there are different points of view regarding this issue in both domestic and foreign psychology.

Burnout is a long-term process characterized by chronic dysfunction and is a relatively independent phenomenon, the distinctive features of which are its maladaptation nature and professional orientation. Today, many specialists of various professions are subject to the burnout syndrome, and employees of educational organizations are no exception, since the latter experience high psychoemotional loads and are often in stressful working conditions.

To prevent and prevent burnout, teachers should follow various recommendations: periodically take a break from work; improve skills and abilities for self-regulation; constantly strive for professional growth, improve the level of knowledge; maintain friendly, favorable contact with the environment, etc. As a condition for the prevention of professional burnout of employees of educational organizations, it is necessary to consider a set of different methods and methods by which it is possible to carry out this process.

\section{References}

1. K.A. Abulkhanova-Slavske, Y.I. Aleksandrov, The Results of competitions the Russian Foundation for Humanities on the problems of integrated study of man, psychology and pedagogy, Bulletin of the Russian humanitarian science Foundation, 2, 20-24 (1999)

2. B.G. Ananyev et al., Personality, subject of activity, individuality, 134 (Moscow: Direct-Media, 2008)

3. E.A. Klimov et al., Psychology of work, 249-249 (Yurayt Publishing House, 2016)

4. V.D. Shadrikov, New model of the specialist: innovative training and competence approach, Higher education today, 8, 26-31 (2004)

5. S.P. Beznosov, Professional deformations of the personality, Bulletin of the Saint Petersburg University of the Ministry of internal Affairs of Russia, 55(3), 167-171 (2012)

6. T.A. Zhalagina, Psychological prevention of professional deformation of the personality of a University teacher, 309 (dis., Tver, 2004) 
7. E.F. Zeer, Psychology of professions, 329 (Moscow, Academic Project, Business Book, 2003)

8. E.Yu. Pryazhnikova, N.S. Pryazhnikov, Career Guidance, 496-496 (Publishing center Academy, 2013)

9. N.E. Vodopyanova, Burnout syndrome, 24 (Publishing house Peter, 2007)

10. A.B. Bakker, E. Demerouti, W.B. Schaufeli, Validation of the Maslach burnout inventory-general survey: an internet study, Anxiety, Stress \& Coping, 15(3), 245-260 (2002)

11. V.V. Boyko, Energy of emotions, 474 (St. Petersburg: Piter, 2004)

12. V.A. Polotsky, Psychology of professional activity: problems, current state and prospects of development, Psychology of professional activity: problems, current state and prospects of development, 161-167 (2019)

13. M.P. Leiter, K.A. Meechan, Role structure and burnout in the field of human services, The Journal of Applied Behavioral Science, 22, 1, 47-52 (1986)

14. H.J. Freudenberger, Staff Burnout, Journal of Social Issues, 30, 1, 159-165 (1974)

15. C. Maslach, S.E. Jackson et al., Maslach burnout inventory, Consulting psychologists press, 21, 3463-3464 (1986) 